\title{
Online Community Response to Major Disaster: A Study of Tianya Forum in the 2008 Sichuan Earthquake
}

\author{
Yan $\mathrm{Qu}$ \\ University of Maryland \\ yanqu@umd.edu
}

\author{
Philip Fei Wu \\ University of Maryland \\ fwu@umd.edu
}

\author{
Xiaoqing Wang \\ University of Maryland \\ xiaoqingw@gmail.com
}

\begin{abstract}
Immediately after the 2008 Sichuan Earthquake, the netizens reacted and participated in the disaster response in many ways. This work examined a popular Chinese discussion forum during the first week after the earthquake, adopting both quantitative and qualitative approaches. A new message classification scheme was developed to categorize 2,266 discussion threads posted to the forum. Four important roles played by the forum were identified and further examined. Design implications for disaster response systems were drawn.
\end{abstract}

\section{Introduction}

China's Sichuan Earthquake occurred in Wenchuan, Sichuan province, China, May 12, 2008, 14:28 local time. It was measured at $8.0 \mathrm{M}_{\mathrm{s}}$ according to China Seismological Bureau. The earthquake affected a large geographic area in China, with 69,170 confirmed dead until June 15, 2008, hundreds of thousands injured, and millions of people homeless. Immediately after the earthquake, the Web became one of the major places for people to share information, express feelings and opinions, and exchange mutual support. It is amazing to see how fast the netizens reacted to the earthquake and how their behaviors affected the emergency response of the government and the whole society. [1]

Launched in March 1999 and now partnered with Google China, Tianya has about 20 million registered users by early 2007 and ranked 21 in the country's most visited sites (from Alexa.com). The Bulletin Board System (BBS) attracts more than 1.5 million page views per day. People go there to discuss a wide range of topics and issues. Anyone can start a discussion thread by posting a new message. The thread then grows when replies follow the original message. The Sichuan earthquake caused a surge of online discussions on earthquake-related topics all over the Internet. Tianya's popularity and its swift reaction to the earthquake made it an ideal site for our study.

We contribute to the existing literature on emergency response systems by creating and conducting analyses based on a new thread classification scheme, which facilitates the understanding of various roles played by online communities in response to a disaster. To create the classification scheme, we sampled discussion threads on two major earthquake-related boards (sub-forums focusing on a particular subject) on Tianya during the first week after the earthquake. Four major roles of the community in disaster response were identified and analyzed using both quantitative and qualitative methods.

The rest of the paper is organized as follows: Section 2 reviews related work on citizen-driven emergency response enabled by information and communication technologies. Section 3 describes the research methods. Section 4 presents the new classification scheme and results of both quantitative and qualitative analysis of sampled threads. Section 5 discusses the implications for system design. The paper concludes with a discussion of limitations and directions for future study.

\section{Related work}

Traditionally, researchers and practitioners have subscribed to the belief that emergency response is a task for trained professionals such as police officers and firefighters. Past research has tended to focus on studying information and communication technologies (ICTs) from the perspective of supporting emergency management, decision making, and field operation (e.g., [2],[3]). In recent years, however, a small but rapidly growing body of literature has revealed the potential of ICTs in citizen-driven emergency response.

During and after the hurricanes that struck the Gulf Coast in 2004 and 2005, the Internet access provided by public libraries in the affected areas was of 
tremendous importance to the affected communities. Community residents used these library computers to check for news and updates about conditions, to locate missing or displaced family members, and to communicate with friends and relatives [4]. Similarly, research about the Pentalk Network - a grassroots computer network set up for farmers and their families at the height of the foot and mouth disease crisis in the UK - revealed how the computer network not only served as an alternative information dissemination mechanism, but also provided a virtual space for interpersonal contact, community discussion, and mutual help among farmers at a critical time [5]. Torrey et al also found that online communities can play an important role in both information access and trust development in disaster relief, and discussion forums are more sustainable in disaster relief than blogs [6].

Recent evidence shows that the public seeks out information from all available sources in the immediate post-disaster time period to make sense of the situation, regardless of whether the source is considered authoritative or not [7]. At the same time, engaged citizens also use all types of ICT applications (especially social media) available at the time to contribute valuable information to authorities and the public. For example, during the 2007 California wildfires, residents in the affected area used Web 2.0 applications such as Google Mashup and Twitter to report and disseminate real-time updates about the crisis [8]. "Citizen journalism" [9] has become such a significant phenomenon that almost all major newspapers and TV stations now encourage their audience to contribute content that is of news value through their websites (e.g., the iReport function on CNN.com). In addition to sharing and seeking facts and opinions, people also improvise in using Web 2.0 technologies to facilitate problem-solving and action coordination. Palen et al. reported that Virginia Tech students and family used Wikipedia to collectively generate an accurate list of 32 victims before the university released the information [10]. Torrey et al analyzed how online communities responded to Katrina by facilitating the distribution of donated goods ("connected giving") from ordinary people to hurricane victims [6]. A research group at the University of Maryland is prototyping a socialnetworking-based response system that promotes peerto-peer assistance in campus emergencies [11].

Although scholarly interest on ICTenabled grassroots emergency response is increasing, this area of research is still at its preliminary stage. Most existing studies either were still attempting to establish a theoretical framework in understanding the phenomenon or relied heavily on anecdotal evidence. Large-scale, systematic empirical studies are still lacking. Studies on Chinese online communities often centered on political issues such as democracy and nationalism (e.g., [12]), whereas systematic studies from the information systems perspective are rare.

Combining textual analysis, "netnography" [13] and quantitative analysis, this study investigated how netizens in one of the largest online Chinese discussion forums responded to China's disastrous Sichuan Earthquake in May 2008. Textual analysis has been deemed useful in studying information behavior and social interactions in online communities such as newsgroups [14]) and health discussion forums [15]. Extending the traditional ethnographic methods from physical locations to computer-mediated environments, netnography has been used in a few recent studies to capture rich, contextual information in online citizen's responses to emergencies [10] [16].

\section{Methods}

To understand how the Tianya community reacted to the earthquake, we adopted a mixed approach with both quantitative and qualitative analysis. First we developed a classification scheme based on a sample of discussion threads from Tianya in the first week after the quake. Using the classification scheme, we manually categorized 2,266 message threads from Tianya. Descriptive and quantitative analysis based on the classification result yielded four major roles of the online forum in disaster response. Then, qualitative analysis based on the content of selected message threads, observations of the forum, and anecdotes provided a comprehensive view of the four roles.

\subsection{Developing a thread classification scheme}

We adopted a mixed (both top-down and bottomup) categorization process to create a non-exclusive classification scheme for discussion threads in the forum, based on both existing literature and our analyses of message content in the forum.

Previous work has examined various roles played by participants in online discussion forums and by people who are facing disasters. Benne \& Sheats categorized online group membership roles into three major categories: task roles, social-emotional roles, and individualistic roles [17]. Kendra and Wachtendorf examined the "social convergence" after the 9/11 attacks and described seven types of social roles: the anxious, the returnees, the curious, the helpers, the exploiters, the mourners, and the supporters [18]. Although these classification schemes offered valuable ideas, the unique goal of this study - to understand 
how people in an online community respond to a national-wide disaster - prompted us to develop a new coding scheme.

Emergency response requires reliable communication, coordination, and delivery of service. During and after the disaster, many people also needed assistance with their physical and mental health. Therefore, in this study, we paid special attention to how Tianya served as part of a large socio-technical system to fulfill those purposes. Tianya forum is not part of the official disaster response system. Hence, we view the online community as a valuable extension to the traditional disaster response system, in aspects such as information gathering and dissemination.

To identify the roles of the Tianya forum in the earthquake, three researchers browsed through about 4300 earthquake-related threads on Tianya between May 12 and 14 and collaboratively developed an initial coding scheme. Two researchers then independently coded 100 random threads from the 4300 set using the initial coding scheme. Cohen's kappa was acceptable in the information categories, but lower in others. The two researchers discussed the inconsistencies in their coding of the 100 threads. After refining the coding scheme, they used it to each code another 50 random threads from the 4300 set. They compared their coding and revised the classification scheme one more time before using it on the full sample.

\subsection{Sampling}

Sample threads were extracted from two subforums on Tianya: MiscTalk and Earthquake. Immediately after the earthquake, people gathered on MiscTalk to exchange information. Because of the high volume in the forum, a board originally called Mutual Help is renamed Earthquake on May $14^{\text {th }}$. Since then, that board became the "official" place to post earthquake-related messages. Although some people continued to talk about the earthquake in MiscTalk, most of the traffic was successfully re-directed to the Earthquake board. Therefore, we sampled threads from MiscTalk from May 12-14, which has a total of 15,635 new threads; and from the Earthquake board from May 14-19, which has a total of 46,280 new threads. The content on both boards are qualitatively similar that we combined the threads from both of them in the analysis. More than $20 \%$ of the posted threads were deleted by board moderators because of inappropriate content. A random sampling of 5\% of the remaining threads on the two boards in the said timeframe resulted in a final sample of 2,266 threads.

\subsection{Classifying sample threads}

Two researchers each coded half of the 2,266 threads in the sample independently based on the final coding scheme. In order to evaluate inter-coder reliability, they both coded 100 random threads in the sample. The overall agreement between the two raters was $88 \%$, and the average kappa is 0.67 . Kappa for all of the four main categories were acceptable, ranging from 0.55 to 0.82 (except the 'other' category, which has an agreement of $92 \%$ but a kappa of 0.3 ). The two raters achieved acceptable agreement on most of the sub-categories (kappa $>0.5$ ), except 'other opinion' and 'sense-making'. These two sub-categories were thus not used in the quantitative analysis. Next, we present the categorization results of the 2266 threads, followed by detailed analysis of each category.

\section{Results}

\subsection{Categorization of discussion threads}

All the sampled discussion threads were categorized into 16 non-exclusive classes, which were then grouped into 8 higher level categories (Table 1). This classification scheme revealed four major roles that Tianya played in this national disaster:

- Information-related. Effective and robust information exchange is extremely important for disaster response. The most important role of the forum is information sharing, seeking, gathering and integrating. Compared with other media such as news websites, the forum is particularly powerful in gathering and integrating information from users.

- Opinion-related. Although seldom mentioned in disaster response literature, the expressing and exchange of opinions by community members may shape public opinions, provide feedback to authorities, and influence response policy. As a Bulletin Board System, Tianya is a natural platform for people to express and discuss different opinions.

- Action-related. Planning and coordinating actions are important functions of disaster response systems. Although there were not as many actionrelated threads as other types of threads on Tianya, we identified discussions on proposing, coordinating, and participating in rescue actions.

- Emotion-related. Emotional support is often needed in disaster recovery. Although most Tianya users are not direct victims of the earthquake, they need this online space to express their personal feelings and concerns and to provide comfort and sympathy to others. A considerable portion of the treads fell under this category. 
Table 1: Thread classification

\begin{tabular}{|c|c|}
\hline Category & Description \\
\hline \multicolumn{2}{|c|}{ Information-related } \\
\hline Sharing & $\begin{array}{l}\text { Providing factual information to the } \\
\text { community }\end{array}$ \\
\hline Seeking & $\begin{array}{l}\text { Soliciting specific factual information } \\
\text { from other community members }\end{array}$ \\
\hline $\begin{array}{l}\text { Gathering and } \\
\text { Integrating }\end{array}$ & $\begin{array}{l}\text { Gathering and integrating factual } \\
\text { information from other community } \\
\text { members to form a "knowledgebase" } \\
\text { collectively on a specific issue or topic }\end{array}$ \\
\hline \multicolumn{2}{|c|}{ Opinion-related } \\
\hline Criticizing & $\begin{array}{l}\text { Criticizing the government, } \\
\text { organizations, or individuals }\end{array}$ \\
\hline Other opinion & $\begin{array}{l}\text { Appraising; providing comments without } \\
\text { explicit appraising or criticizing; or } \\
\text { seeking opinions from others }\end{array}$ \\
\hline \multicolumn{2}{|l|}{ Action-related } \\
\hline General & Proposing actions to the general public \\
\hline $\begin{array}{r}\text { Individual } \\
\text { participation }\end{array}$ & $\begin{array}{l}\text { Declaring actions performed by, or to be } \\
\text { performed by the author }\end{array}$ \\
\hline Coordinating & $\begin{array}{l}\text { Organizing actions among a group of } \\
\text { forum users }\end{array}$ \\
\hline \multicolumn{2}{|c|}{ Emotion-related } \\
\hline Expressing & $\begin{array}{l}\text { Expressing personal feelings such as } \\
\text { anxiety, sadness, anger, proud, etc. }\end{array}$ \\
\hline $\begin{array}{r}\text { Emotional } \\
\text { support }\end{array}$ & $\begin{array}{l}\text { Demonstrating social and emotional } \\
\text { support, including mourning, blessing, } \\
\text { comforting, encouraging and expressing } \\
\text { concerns for victims. }\end{array}$ \\
\hline \multicolumn{2}{|c|}{ Community building } \\
\hline $\begin{array}{r}\text { Moderation- } \\
\text { related }\end{array}$ & $\begin{array}{l}\text { Posts by the moderators; the forum users' } \\
\text { request for moderation; and users' } \\
\text { responses to moderation activities }\end{array}$ \\
\hline Norm shaping & $\begin{array}{l}\text { Forum users' attempts to regulate others' } \\
\text { behaviors in the forum }\end{array}$ \\
\hline Sense-making & $\begin{array}{l}\text { Making connections among pieces of } \\
\text { information in order to understand the } \\
\text { occurrence of the earthquake or to } \\
\text { interpret other related events }\end{array}$ \\
\hline \multicolumn{2}{|l|}{ Anti-Social } \\
\hline Flaming & $\begin{array}{l}\text { Using insulting or hostile language to } \\
\text { personally attack a person or a group }\end{array}$ \\
\hline Trolling & $\begin{array}{l}\text { Posting irrelevant or off-topic messages } \\
\text { with the intention of baiting community } \\
\text { members into an emotional response }\end{array}$ \\
\hline Off-topic & Messages irrelevant to the earthquake. \\
\hline
\end{tabular}

The thread classification outlined the reaction of a large online forum to a national disaster. The four major top-level categories correspond to four ways the forum can help in disaster response. A closer examination of the categories and threads will shed more light on how to utilize such a public forum in disaster response.

\subsection{Thread analysis}

4.2.1 Overall trend. We counted the total number of threads in the two boards during the first week after the quake. Figure 1 shows that the total number of threads from the two boards almost doubled in the first four days and started to decrease only on May 17. On May 18 and 19, thread volume increased again, possibly due to the official announcement on the 18th that May 1921 were designated as the national mourning days. The announcement might have renewed people's attention and caused a new surge of postings.



Figure 1: Total number of new threads by subforum by day

Figure 2 shows the percentage of threads in each category in our sample on each day. Informationrelated $(37.3 \%)$ and opinion-related threads $(32.1 \%)$ are two categories that dominated the forum, followed by emotion-related (14.2\%) and action-related (10.7\%) threads. The figure demonstrates the shifting needs of community members as the disaster unfolded. When a disaster strikes, people first need to gather and share factual information in order to learn what happens. As more information is gathered, people are ready to express their opinions. When the community transits into the recovery phase, action- and emotion-related discussions increase.

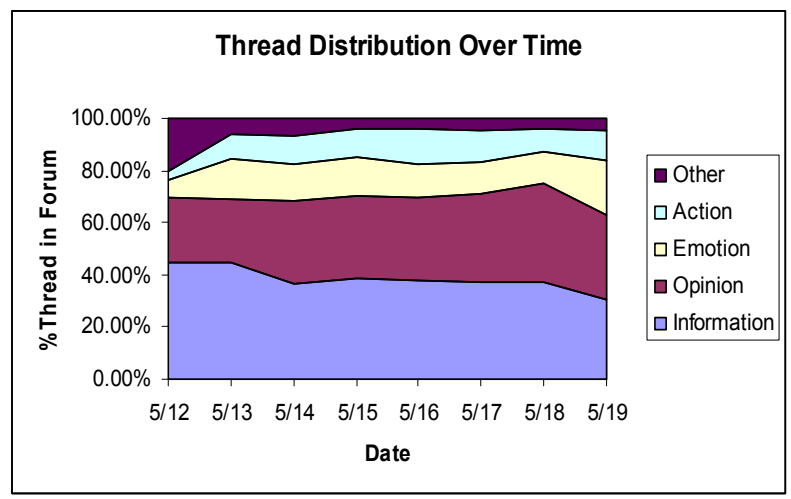

Figure 2: Percentage of new threads by category

*The categories are not mutually exclusive. The same message can fall into multiple categories. 
4.2.2 Thread view and thread length. To assess Tianya's major roles in the disaster response, we examined characteristics of different threads. We collected number of views and length of each sampled thread until June 12, 2008. Thread views refer to the number of times a thread is clicked and thread length is the total number of messages in the same thread, including the initial message and the replies. Both variables are indicators of users' level of participation in the community.

The two boards were very active during the studied time frame. A few threads in our sample attracted extremely high number of responses, with the longest thread receiving about 15 thousand responses and 2 million views. Distributions of the message views and thread length are highly skewed. On average, a thread in our sample had 46.8 messages and was viewed 3333.3 times in one month. However, the median number of posts in a thread is 3 , and the median number of views is 190 . To prevent extreme cases from biasing our analyses, we excluded 22 extremely long threads (threads containing more than 500 replies) from the 2266 in the sample.

Figure 3 shows the average thread length and average views per thread for each main category, excluding the threads with more than 500 replies. Threads posted in the first three days were read and replied more often than those posted later on. Threads posted on May $12^{\text {th }}$ received the highest number of replies (Figure 3a). This suggests that quake-related posts on the day of the quake attracted more attention than other posts. Threads posted on May $14^{\text {th }}$ were viewed most often (Figure $3 \mathrm{~b}$ ), possibly due to the transition of quake-related discussion from the MiscTalk board to the Earthquake board, which resulted in the copy of important or popular messages to the Earthquake board, which would later attracted more views than ordinary posts.

To examine how people reacted to threads of different types, we regressed thread view and thread length (log transformed) on a series of dummy variables representing each subcategory. The regression results are not reported due to limited space. Some interesting findings are summarized below.

Information sharing threads were read more often than other threads, consistent with the information dissemination function of Tianya. Information gathering and integrating threads were viewed and replied more often than others, suggesting that people found much value in such integrated content from multiple sources. In some cases, people responded to such threads simply because they wanted to keep the thread visible to others (Tianya ranked the most recently updated threads on top).
Opinion-related threads also received much attention from the forum users. Threads that criticized the government, organizations, celebrities or fellow forum users were viewed and responded significantly more often than other types of threads, which suggests that Tianya users tended to engage in long debates when they disagreed with one another.

Surprisingly, action-related threads received significantly fewer views and no more responses than threads of other types. There are a couple of possible explanations. First, a post calling for action often has a title that clearly indicates its content of the post. Therefore, only those who are interested in the action or are capable of helping would read and respond to the post. Because many actions need to be conducted locally, only a small portion of Tianya members can actually participate. Second, Tianya's main function is a discussion forum. Most people join Tianya to exchange information and engage in discussions. They may not be familiar with planning and coordinating actions on such a bulletin board.

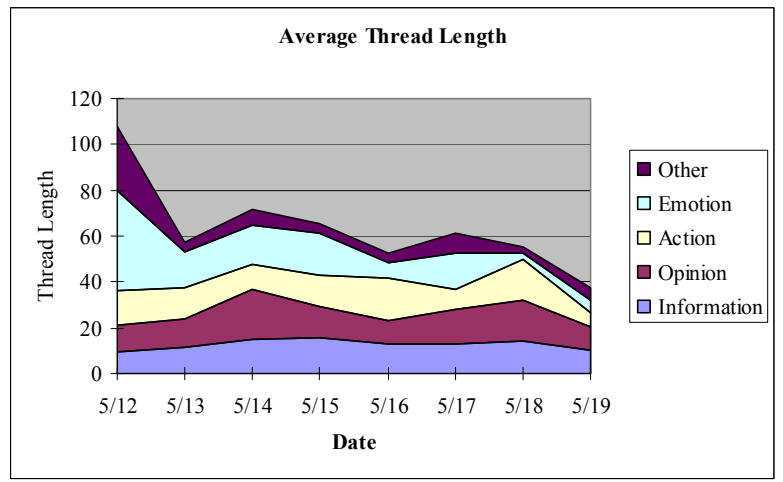

Figure 3a: Average thread length, by category

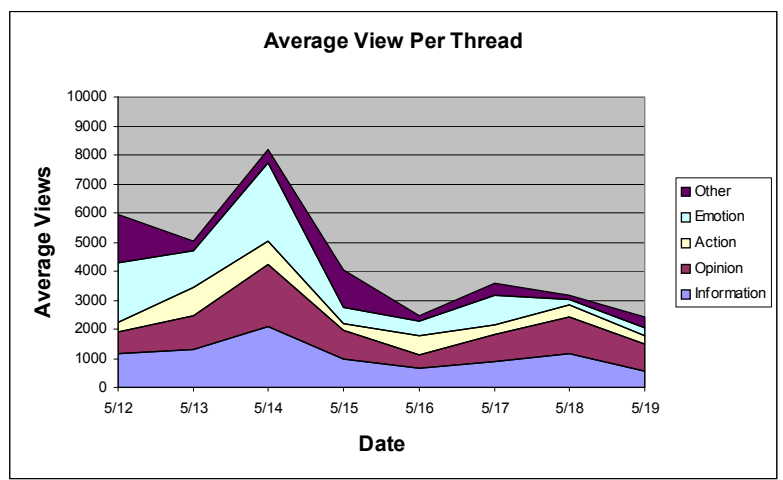

Figure 3b: Average views per thread, by category

Similarly, emotional support threads were read less often and received fewer replies. One possible explanation is that although many people expressed their support for the victims, the content of those posts 
was very similar (e.g., morning, blessing, encouraging) and did not add value to other forum participants.

Finally, threads that attempted to develop or reshape norms in the forum were read less often than others, although they received similar number of replies as threads of other types. These surprising results warrant more detailed examination into the nature and content of the threads.

In summary, the regression result suggests that people preferred to read threads that share information, gather and integrate information, or criticize others, but tended not to read threads that describe or require an action, provide emotional support, or shape the community norms. People preferred to reply to threads that gather and integrate information and those that criticize others, but tended not to reply to threads describing the author's participation in disaster relief or providing emotional support. Although informationrelated and opinion-related threads seemed to be successful in attracting people's attention and participation, those that are action- or emotion-related were less so.

\subsection{Roles of online forum in disaster response}

After the quantitative analysis, we took a closer look at the message content of some sample threads to gain a deeper understanding of how the forum fulfilled its four major roles. This section describes key insights from our observations.

4.3.1 Information-related threads. In response to the disaster, Tianya served as a platform for various information behaviors such as information sharing, seeking, gathering, and integrating. Large number of information-related threads was generated everyday. We first discuss how the informational functions were fulfilled by the forum below.

Online forum as information sources. The regression analysis suggested that information sharing, gathering and integrating threads received more attention from forum users. Information distributed on the forum came from both authoritative and personal sources. Although authoritative information was often cited from major news websites, such posts on Tianya were often augmented by additional discussions and supplementary information. Personal experience, especially integrated personal experience, becomes an important information source during the quake for both the community members and the media. The first quake reporting news articles on one of the most popular news website in China - Sina.com.cn - were based on personal experiences of the reporters or their informal social network through IM, chat rooms and public online forums.

However, as in any open online communities, it is a challenge to evaluate the authenticity of information provided by members, to control information quality, and to prevent rumors. We have seen evidence of rumors spreading on the forum, causing some degree of panic. Some people even showed doubts on authentic reports, especially when the source of the reports was not specified. The major mechanisms that Tianya members used to clarify rumors and resolve doubts included cross-validating with other people's personal experience, seeking further information, and comparing with official announcements and news. Because of the importance of clarifying rumors after the quake, Tianya forum administrators created a special thread dedicated to gathering unconfirmed information and clarifying rumors. Any content from trustable sources that supported or disproved unconfirmed information was highlighted with a different color by moderators.

Online forum as part of the communication network. The online forum also provided an effective communication channel, especially when many other communication channels were damaged in the quake. Immediately after the quake, phone communication (both cell phone and landline) in Sichuan province was paralyzed due to the damage of telecommunication infrastructure and the surge of phone calls. Much valuable information about the quake was sent out through the Internet, and the Internet became the major channel for people all over China to keep in touch with those in Sichuan.

Meanwhile, Tianya as part of a larger online social network helped ordinary people to communicate to the authority. For example, the military had difficulty finding a good helicopter landing spot in a heavily impacted area to send in rescue troops. A college student who grew up in that area posted a detailed message online about a potential landing spot and pleaded the readers to forward the important information to authorities. The message was forwarded thousands of times and soon appeared in almost all major online forums. The military then contacted the girl and successfully landed a helicopter on the spot she described.

Information gathering and integration. Our regression analysis showed that integrated information was much valued by Tianya users. The speed and the scale of information gathering and integration on the forum were impressive. The first quake-reporting message appeared less than a minute after the earthquake occurred (14:28). Within 10 minutes after 
the quake, 56 threads reported feeling of earthquake from 22 different cities in China. Figure 4 is a map mashup showing user-reported earthquake locations. Within the first hour, about 350 threads on earthquake were created in the MiscTalk board. The longest thread contained 535 reports on the earthquake from 105 cities in China.

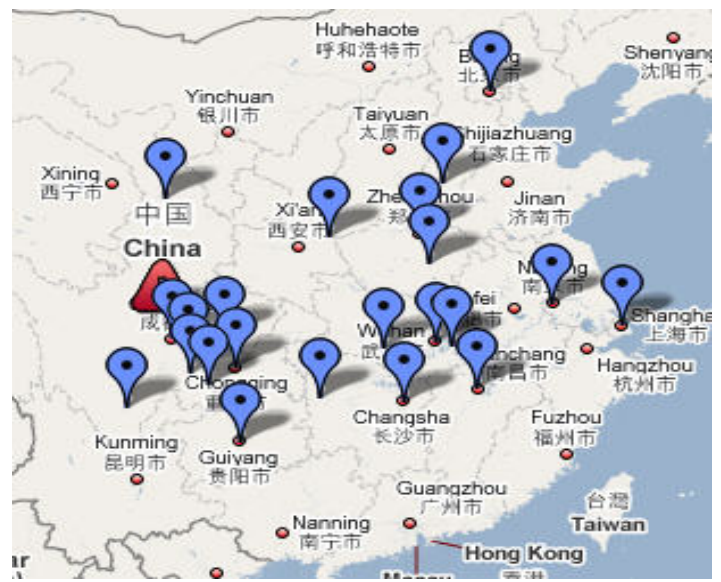

Figure 4: A map mashup on Tianya showing userreported earthquake locations (The epicenter is marked by the red alert sign)

Several mechanisms facilitated information gathering and integration in Tianya. When the earthquake occurred, threads were quickly created for people to report the location and level of the earthquake. Later, threads were opened for people to report missing family members and friends. To attract more attention to these threads, forum moderators quickly "highlighted" several information integration threads by changing the font and color of the title of the threads. A few of the information gathering threads were even placed at a digest area on the homepage of the forum. At the same time, the Tianya system allowed administers to embed a survey in a thread to integrate information and show the results. A survey of earthquake location was posted in one of the information gathering thread within the first hour after the earthquake started and quickly gathered thousands of responses.

Information seeking in large scale public forum. Our regression analysis did not find that information seeking threads receive more or less attention than other types. Thus, we cannot tell if the forum was effective in fulfilling users' information seeking needs. To better assess the successfulness of the information seeking behavior, we examined 173 posts that explicitly requested information. Among the 173 posts, $84(48.6 \%)$ were provided with relevant information in the replies, suggesting moderate success rate. We then examined posts requesting specific information: Among 39 posts seeking information of family member and friends, $13(33 \%)$ received useful information: Among 27 posts seeking donation and rescue participation information, $15(56 \%)$ received useful information. These success rates are reasonably high considering that a thread would quickly "sink" and be ranked out of the first few pages on such a highly active forum.

4.3.2 Opinion-related threads. One of the main purposes of Tianya as a discussion forum is for community members to express and exchange opinions. As shown earlier, a large portion of threads were coded in the opinion category (32.1\%), and criticizing threads $(12 \%)$ were more likely to be read and replied to. From our observations of opinion-related threads, Tianya not only provided a useful platform for opinion exchange, but also influenced the community members' and the public's opinion.

As one of the most popular online forums in China, the opinions expressed in Tianya reflected public opinions on various issues and were cited by traditional media frequently (e.g. [19]). The forum acted as a feedback mechanism for both individuals and the government to adjust behaviors. For example, a message on possible embezzlement of salvation tent raised a wave of angry posts. The government then quickly investigated and punished the responsible officials. In another example, a famous entrepreneur was heavily criticized by donating only 0.3 million dollars and asking his employees not to donate more than $\$ 1.5$ per person. Under the huge pressure generated from the netizens, the entrepreneur apologized publicly 9 days later and promised to donate another 1.5 million dollars. Although Tianya was not the only Web-based community participating in this type of informal control and feedback mechanisms, it certainly played an important role as one of the leading communities.

The opinion-related threads, particularly the ones that criticize, tended to generate long debates in the forum. These debates are social processes of collaborative sensemaking and norm shaping. According to Weick [20], when community members have diverse interests and experiences, conflict, domination, and contradiction play an important role in sensemaking at both individual and group levels. Being exposed to different ideas and interpretations, people re-examine their opinions, create common understandings as well as "the spirit of contradiction" [21]. During the quake, the forum acknowledged and accommodated different interpretations and opinions, and allowed the users to make their own judgments. For example, several threads listing the donation 
amounts by big companies and celebrities generated a heated discussion. At the beginning, companies and individuals who donated large amount were praised, and those who donated less or none were denounced. Later, a minority voice started calling such comparison "norm abduct", and suggested netizens not to judge others by the amount of money they donated but their good intention. During the debate between the two sides, many people were exposed to and started reflect on different opinions. Eventually, a norm was established in the community to not to criticize donators by the donation amount.

4.3.3 Action-related threads. Resident-to-resident assistance has been proved critical in large-scale disaster responses. ICTs have greatly increased people's capability to reach those who are in need of help and to coordinate actions across time and space. Although there may only be a small portion of the Tianya members who were interested in disaster relief and rescue, the massive number of Tianya members provided the critical mass that made the community an important source of relief activities. In fact, a lot of the action-related discussions were a combination of information dissemination and action coordination. The Tianya community provided valuable and timely information that the officials may not have been able to collect. Moreover, Tianya provided enough eyeballs that filtered the information and forwarded the most critical ones - requests for immediate help to a certain individual or a group of people - to all other major communities on the Internet and the appropriate officials to prompt action. For example, a soldier who was dispatched to Wenchuan posted a message saying that his pregnant wife needed daily supplies and medical care while he was away. The post soon caught a lot of netizens' attention and was distributed all over the cyberspace. A few days after the request, the soldier's wife made an announcement on Tianya stating that she received lots of help, thanks to the widespread attention that the forum brought up.

The effectiveness of Tianya in emergency relief is also reflected in its ability to solicit donations. One of the most popular action-related threads is a relief foundation's request for donations, which listed multiple donation channels and detailed instructions for donating both money and physical goods. The thread indicated the foundation's cooperation with both other relief organizations and the officials, and that it is directly participating in earthquake relief in the Sichuan province. By providing daily reports on the amount of donations received and the process of donation distribution procedures, the thread gained swift trust from the Tianya members. The foundation collected over 6.3 million dollars by noon on May 22 from over 660,000 online individual donors.

Meanwhile, many relief organizations and volunteers used Tianya as the major communication mechanism when coordinating relief actions between the netizens, the volunteers and the officials. Often times, volunteers working in Sichuan posted the most needed rescue materials, such as tents, gloves, masks and other medical resources, on Tianya and requested people to collect and send them to Sichuan. Relief organizations and volunteers would work with the Chinese government to secure the fastest distribution channels for these needed materials to reach Sichuan. All the distribution methods were updated on Tianya as well. When individuals volunteered to travel to Sichuan to help, they would post their travel plan and contact information online so that they could personally collect and bring rescue materials to the people in need. These coordination efforts were only possible with the close monitoring and active participation of the Chinese netizens, which reduced the workload of the government and enabled China's swift response during the Earthquake.

There were many other successful stories at the community level that demonstrated the power of grassroots actions. We have also seen a handful of posts that tried to coordinate volunteer rescue actions or reported personal volunteer experiences. Since Tianya has another sub-board called "Volunteers" which was dedicated to volunteering discussions, there may be a wider range of relief-related events discussed in that board that we have not observed on the two boards that we studied.

4.3.4 Emotion-related threads. There have been many studies on how community members provide emotional support to one another. In fact, about 14 percent of our sampled threads are emotion-related. People came to the forum to express all kinds of emotions: sorrow, anger, empathy, pride, and so on. Interestingly, we didn't find much interaction among community members in this type of threads. In other words, although many Tianya members used the forum as a place to leash out their feelings, they did not seem to receive much comfort from or give comfort to other members. There were a few long threads that aggregated people's emotional and spiritual support for all the victims and people in need, as well as strong support for the Chinese rescue army working in Sichuan. However, most emotion-related threads tended to be short. This may be due to the fact that the huge crowds in Tianya are only loosely connected. There exist few or no close-knit social networks in Tianya, unlike some small online communities (e.g., Bob's WWWBoard described in [15]) where members 
are more tightly related. In addition, as a basic Bulletin Board System (BBS), Tianya lacks support for multimedia content such as member avatar and emoticons. In computer-mediated communications, these graphic icons compensate the lack of visual cues that many believed are critical in assisting socioemotional interactions [23].

4.3.5 Community building. At the peak time of the forum traffic, there were hundreds of new posts or replies every minute. Some efforts have been put in by Tianya administrators to solve the problem of information overload. Several sub-boards with different topics were created on the Earthquake board, with the intention to better organize the vast amount of traffic on the community. However, many Tianya users appeared to ignore those ad-hoc rules about where their messages should be posted. Moreover, there were many duplicate posts inside the Tianya community, as people cross-posted messages in different boards to catch attention. The board moderators attempted to discourage or even remove posts that were either anti-social or deemed useless to the community. The users, however, sometimes disagreed and debated with the moderators' decisions.

While the moderators struggled with top-down community governance, some community participants showed a strong consciousness of self-regulation. When Tianya was flooded with messages of anger, panic, depression, and flaming, a post called "Chinese Netizen Self-Regulation Code of Conduct" was posted by a user and applauded by many Tianya community members. The post listed ten "don'ts" such as "don't panic", "don't spread rumor", "don't flame", among others. This "Code of Conduct" was reposted by netizens in many other online communities. Our sample data also show that "norm-shaping" was a consistent theme among the posts.

\section{System design implications}

Although online bulletin boards like Tianya were not designed to deal with disaster response, our research suggests that such a system could be a valuable extension to traditional disaster response systems, through harnessing the collective power of netizens in exchanging and disseminating information, shaping public opinions, providing a quick feedback mechanism, coordinating actions and offering emotional support.

Although human input has long been recognized as important in emergency response, existing crisis response systems do not systematically exploit the potentials of "human as sensor" [24]. Tianya demonstrated the value of public participation in providing vital information for both average citizens and emergency response professionals. A crisis management system may gather valuable information scattered all over the Internet by systematically crawling major online communities. This can be done automatically with well-designed crawling robot, or through human-assisted crawling performed by online community administrators who serve as the intermediary between citizens and crisis management professionals.

In fact, the XunQin ("Finding Relatives") service (http://www.google.cn/intl/zh-CN/qinren/cse.html)

provided by Google (China) during the earthquake has already shown some interesting opportunities in collecting user-contributed information and making use of online communities in disaster response. The three main functionalities of the Google XunQin system were: 1) indexing victims' names released by hospitals so that one could use the system to locate/verify relatives and friends in a specific hospital; 2) indexing "Where are you?" and "I'm OK" messages posted in five major Chinese online communities (including Tianya); 3) providing a "batch posting" function to allow a message submitted through XunQin to be automatically posted in all the five online communities at once. The Google XunQin service became quite successful and helped thousands find their relatives.

Other than crawling and monitoring online community discussions as important information sources, the government and disaster response professionals can also utilize such systems to automatically analyze public opinions, identify most discussed issues to be addressed, and streamline information distribution to the netizens who are willing to participate in disaster relief. For instance, automatic information filtering mechanisms can quickly identify issues that repeat most frequently, or identify posts that require immediate attention. Information of similar nature that is posted in multiple action-related threads can be automatically integrated to better coordinate relief actions. Official updates on donation channels, needed materials, and volunteering procedures can be pushed to all major communities automatically rather than relying on individuals to collect and integrate them manually.

In our study, we found certain design features that allowed Tianya to quickly adapt to the disastrous event and support community response. Tianya forum administrators had the ability to reorganize content by creating new sub-boards, highlight important threads and reposition them on the homepage, and create new administrative routines (e.g. the creation of roster of administrators and moderators). These capabilities 
were important in supporting the smooth functions of the forum during earthquake response.

Several additional features may further benefit an online community when facing emergency situations. Distributed, community-based governance mechanisms, like the social moderation mechanisms in SlashDot and Digg, can be implemented to allow community members to collectively control the information quality and manage discussions, reducing the information overload on forum moderators in an emergency. Moreover, multimedia content can allow more intimate interactions and subtle expressions to better facilitate emotional expression and support.

\section{Conclusion and future study}

As one of the most popular online communities in China, Tianya showcased how the Chinese netizens coped with the Sichuan earthquake and how they used discussion forums for emergency response and recovery. By observing and analyzing earthquakerelated discussions on Tianya, we generated a classification scheme which can be used to categorize disaster-related discussions in online environment. With the classification scheme that we developed, we identified four major ways that the forum supported the community's response to the China earthquake. From our analysis, we found that the forum reacted to the disaster quickly and relatively effectively, particularly in supporting information and opinion roles. Our results shed lights on designing emergency response systems that harness the power of citizen participation, especially during the post-disaster recovery phase.

This study has several limitations. First, even though Tianya is the largest online discussion forum in China, our findings might not be generalizable to other Chinese online forums or other types of online community infrastructure like chat room, IMs, and blogs. Second, we have only examined the threads in the first week after the main shock. There might be important trends that could be revealed by studying the forum for a longer period. Third, people often cross the boundary of systems and communities, but our study only focused on discussions inside one community. A study on a larger network could draw a more comprehensive picture of ICT-enabled grassroots emergency response. Finally, this project shares the limitation of cyberspace research in that only online data in written texts are observable. A follow-up study that surveys or interviews online community participants will give us better ideas of their offline behaviors and private communications.

\section{References}

[1] The Power of Chinese Netizens after the Earthquake, Forbes.com

http://english.ohmynews.com/articleview/article_view.as p?at_code $=434513 \&$ no $=382780 \&$ rel_no $=1$

[2] Schafer, W. A., Ganoe, C. H. and Carroll, J. M. Supporting Community Emergency Management Planning through a Geocollaboration Software Architecture. Computer Supported Cooperative Work, 16, 4-5 (2007), 501-537.

[3] Turoff, M., Chumer, M., Van de Walle, B. and Yao, $\mathrm{X}$. The Design of a Dynamic Emergency Response Management Information System (DERMIS). Journal of Information Technology Theory and Application, 5, 4 (2004), $1-35$.

[4] Jaeger, P. T., Langa, L. A., McClure, C. R. and Bertot, J. C. The 2004 and 2005 Gulf Coast Hurricanes: Evolving Roles and Lessons Learned for Public Libraries in Disaster Preparedness and Community Services. Public Library Quarterly, 25, 3/4 (2007), 199-214.

[5] Hagar, C. and Haythornthwaite, C. Crisis, Farming \& Community. The Journal of Community Informatics, 1, 3 (2005), 41-52.

[6] Torrey, C., Burke, M., Lee, M., Dey, A., Fussell, S. and Kiesler, S. Connected Giving: Ordinary People Coordinating Disaster Relief on the Internet. In Proceedings of the 40th Annual Hawai'i International Conference on System Sciences (HICSS'07) (Hawai'i, USA, 2007).

[7] Sutton, J., Palen, L., and Shklovski, I. Backchannels on the Front Lines: Emergent Use of Social Media in the 2007 Southern California Fires. In Proceedings of the Information Systems for Crisis Response and Management Conference (ISCRAM 2008) (Washington, DC, 2008).

[8] Glaser, M. California Wildfire Coverage by Local Media, Blogs, Twitter, Maps and More. PBS MediaShift. Retrieved November 17, 2007, from http://www.pbs.org/mediashift/2007/10/the_listcalifornia_wil dfire co_1.html

[9] Gillmor, D. We the Media: Grassroots Journalism By the People, For the People. O'Reilly Media, Inc., Sebastopol, CA, 2006.

[10] Palen, L., Vieweg, S., Sutton, J., Liu, S., \& Hughes, A. Crisis informatics: Studying Crisis in a Networked World. In Proceedings of the Third International Conference on ESocial Science (Ann Arbor, MI, 2007).

[11] Wu, P. F., Qu, Y., Preece, J., Fleischmann, K. R., Golbeck, J., Jaeger, P. T. and Shneiderman, B. Community Response Grid (CRG) for a University Campus: Design Requirements and Implications. In Proceedings of the Information Systems for Crisis Response and Management Conference (ISCRAM 2008) (Washington, DC, 2008).

[12] Hughes, C. R. Nationalism in Chinese Cyberspace. Cambridge Review of International Affairs, 13, 2 (2000), 195 $-209$.

[13] Kozinets, R. V. The Field Behind the Screen: Using Netnography for Marketing Research in Online Communities. Journal of Marketing Research, 39, 1 (2002), 61-72. 
[14] Joyce, E., and Kraut, R. E. Predicting continued participation in newsgroups. Journal of Computer-Mediated Communication, $\quad 11, \quad 3 \quad$ (2006), article 3.

[15] Maloney-Krichmar, D. and Preece, J. A Multilevel Analysis of Sociability, Usability, and Community Dynamics in an Online Health Community. ACM Transactions on Computer-Human Interaction (TOCHI), 12, 2 (2005), 201232.

[16] Liu, S., Palen, L., Sutton, J., Hughes, A. and Vieweg, S. In Search of the Bigger Picture: The Emergent Role of On-Line Photo-Sharing in Times of Disaster. In Proceedings of the Information Systems for Crisis Response and Management Conference (ISCRAM 2008) (Washington, DC, 2008).

[17] Benne, K.D. and Sheats, P. Functional Roles of Group Members. Journal of Social Issues, 4 (1948), 41-49.

[18] Kendra, J. M. and Wachtendorf, T. Reconsidering Convergence and Converger: Legitimacy in Response to the World Trade Center Disaster. Research in Social Problems and Public Policy, 11 (2003), 97-122.
[19] Liu, S. Warped View of Right and Wrong. China Daily. Retrieved June 15, 2008 from http://www.chinadaily.com.cn/cndy/200805/28/content 6716375.htm

[20] Weick, K. Sensemaking in Organizations. Sage Publications, Thousand Oaks, CA, 2005.

[21] Billig, M. Arguing and Thinking: A Rhetorical Approach to Social Psychology. Cambridge University Press, Cambridge, UK, 1989.

[22] Derks, D., Bos, A. E. R. and Grumbkow, J. Emoticons and Social Interaction on the Internet: The Importance of Social Context. Computers in Human Behavior, 23, 1 (2007), 842-849.

[23] Mehrotra, S., Butts, C. T., Kalashnikov, D. V., Venkatasubramanian, N., Rao, R., Chockalingam, G., Eguchi, R., Adams, B., and Huyck, C. (2003). Project RESCUE: Challenges in Responding to the Unexpected. SPIE Journal of Electronic Imaging, Displays, and Medical Imaging, 5304, 179-192. 